\title{
A UTILIZAÇÃO DE RECURSOS DA SOCIEDADE DA INFORMAÇÃO NA CRIAÇÃO E DESENVOLVIMENTO DA PRÁTICA PEDAGÓGICA NA DISCIPLINA DE HISTÓRIA
}

\section{ARTIGO ORIGINAL}

CAVALCANTI, Genivaldo Bezerra1, BRAZIL, Paulo Henrique de Assis², BRAZIL, Danielle Farias Vitorino 3

CAVALCANTI, Genivaldo Bezerra. BRAZIL, Paulo Henrique de Assis. BRAZIL, Danielle Farias Vitorino. A utilização de recursos da sociedade da informação na criação e desenvolvimento da prática pedagógica na disciplina de história. Revista Científica Multidisciplinar Núcleo do Conhecimento. Ano. 06, Ed. 10, Vol. 04, pp. 168-177. Outubro 2021. ISSN: 2448-0959, Link de acesso: https://www.nucleodoconhecimento.com.br/educacao/recursos-da-sociedade, DOI: 10.32749/nucleodoconhecimento.com.br/educacao/recursos-da-sociedade

\section{RESUMO}

Em meio ao atual cenário chamado de sociedade da informação e conhecimento caracterizado pelas mudanças de acesso e uso da informação em diversas áreas, inclusive na educação, encontram-se grandes desafios quanto à criação e adequação de práticas pedagógicas capazes de promover o ensino e aprendizagem de forma dinâmica e atrativa diante do tradicionalismo em sala de aula, aspecto comum à disciplina de história. Com isso tem-se como interrogação norteadora deste estudo: A utilização de recursos da sociedade da informação e conhecimento na educação pode servir como apoio a construção de práticas pedagógicas que promovam o ensino e aprendizagem da disciplina de história? O objetivo deste

\footnotetext{
${ }^{1}$ Mestre em Ciências da Educação pela UGF/RJ. ORCID: https://orcid.org/ 0000-0002-6991-819X

2 Mestre em Economia pela UFPB. Pós Graduado em Contabilidade Pública pela Universidade Gama Filho - UGF /RJ. Graduado em Ciências Contábeis pela UFRN. ORCID: https://orcid.org/0000-0002-6890-4669

${ }^{3}$ Pós-Graduada em Contabilidade Pública pela Universidade Gama Filho - UGF /RJ; Graduada em Ciências Contábeis pela UFRN. ORCID: https://orcid.org/0000-0002-6510-9440
}

$\mathrm{RC}: 99007$

Disponível em: https://www.nucleodoconhecimento.com.br/educacao/recursos-dasociedade 
estudo, se utilizando de uma pesquisa exploratória em revisão da literatura existente, visa apresentar as contribuições da atual sociedade da informação buscando um despertar para sua colaboração em recursos, práticas e materiais que podem promover a eficiência e eficácia na transmissão do conhecimento, com o olhar na disciplina de História na cena escolar. A pesquisa se justifica, pois o tema pode apresentar oportunidades de melhoria para gestores e docentes em suas práticas pedagógicas.

Palavras-Chave: sociedade da informação e conhecimento, práticas pedagógicas, disciplina de história.

\section{INTRODUÇÃO}

Segundo Kenski (2012) a sociedade da informação e do conhecimento, termo utilizado no final do século $\mathrm{XX}$, define o modelo atual de vida das pessoas. Desempenha construção de valor e auxílio para o bem-estar e qualidade de vida das pessoas através do acesso e uso das Tecnologias de Informação e Comunicação (TICs) na interação do homem e seu meio.

Para Arruda et al. (2020) O avanço dos meios tecnológicos impõe novas dificuldades de ensino aos professores. Nesse sentido, deve-se focar no aluno como grande beneficiário do conhecimento, por isso, é indispensável que haja interesse do aluno nas disciplinas capaz de proporcionar uma visão do mundo através da compreensão analítica do tempo e espaço, sendo capaz de despertar a criticidade e a consciência dos discentes como é o contexto da disciplina de História.

Cabrini (1986) concorda que desde os primórdios as constantes mudanças e avanços da sociedade exigem do professor, da disciplina de História, uma formação não apenas voltada para o conhecimento da área, mas também conhecimentos multidisciplinares objetivando a complementação das ações pedagógicas solicitadas pelo planejamento escolar no intuito de aumentar o interesse do aluno em sala de aula. Somado a isto, os avanços tecnológicos demandam constante qualificação, o 
que demonstra o quão instigante é a prática docente, seja esta de qualquer área do conhecimento.

A questão que norteia este estudo sobre a utilização de recursos da sociedade da informação e conhecimento na educação para servir como apoio à construção de práticas pedagógicas para a promoção do ensino e aprendizagem desperta questões a serem verificadas que as práticas pedagógicas devem promover meios de possibilitar a realização do ensino e aprendizagem. Para isso as discussões a cerca deste tema na sociedade da informação requer entendimento, compreensão e do professor sobre os recursos que podem ser utilizados na criação ou complementação de antigas ou novas práticas pedagógicas, sobretudo no ensino da disciplina de história.

A metodologia de pesquisa exploratória utilizada neste estudo pretende buscar padrões, ideias ou hipóteses. A intenção não é testar ou confirmar uma determinada hipótese, e sim realizar descobertas. Assim foram analisadas análises em artigos dos últimos 15 anos, de autores da área da educação. As fontes de pesquisa utilizadas foram em meio físico e repositórios digitais. A análise dos documentos buscou a complementação acerca do tema proposto e não o embate de visões dos autores estudados.

O objetivo acerca do assunto proposto é conhecer o cenário da educação diante do modelo atual da sociedade, buscar meios de colaborar para uma proposta de ensino mais dinâmica para a disciplina de História e apresentar recursos capazes de colaborar para a criação de práticas que promovam o ensino e aprendizagem. A principal importância da busca por um modelo capaz de promover uma aula mais atrativa, em especial na disciplina de História é modificar a visão ao qual ela é taxada, como uma de disciplina estática e meramente de decorar dados. No entanto a verdadeira preocupação é pelo entendimento e do relacionamento entre os eventos para se situar no atual momento estudado, podendo assim passar ao aluno que a disciplina de história tem como objetivo a formação de uma identidade, com o papel de construir a noção de "consciência histórica" com os sujeitos.

RC: 99007

Disponível em: https://www.nucleodoconhecimento.com.br/educacao/recursos-dasociedade 


\section{DESENVOLVIMENTO}

\section{O ENSINO DE HISTÓRIA NA CONTEMPONANEIDADE}

Segundo Cabrini (1986) a disciplina de história durante sua trajetória se manteve diante de uma disputa no espaço escolar onde poucos recursos e a pouca capacitação dos professores, restringem o ensinamento a uma grade curricular congelada, pouco atrativa e com poucos espaços físicos capazes de trazer aos alunos locais e pesquisas propícias de entender a disciplina não apenas como resgate de um passado, mas de um processo pragmático da criação de pensamento crítico e formação do indivíduo.

Ainda segundo o autor a disciplina foi concebida com a finalidade de criação do cidadão, continuou como importante instrumento de reflexões sobre a formação do indivíduo para o exercício da democracia, mas também da criação do cidadão capitalista global conforme o ritmo das potências mundiais e incremento de novas tecnologias de um atual mundo globalizado.

Para Knauss (2006, p. 109) e Burke (2004, p.13), nas últimas décadas, o ensino de história veio se modernizando, trazendo novas ideologias. Essa nova forma de abordagem dos conteúdos disciplinares, encontra-se nos Parâmetros Curriculares Nacionais de História (1997 p. 29), que expressaram algumas possibilidades de transformação do ensino da disciplina e apontam especialmente aspectos metodológicos a serem aperfeiçoados na sala de aula. Entre eles, especialmente os que se referem aos conteúdos procedimentais, como a realização de pesquisa por parte dos alunos.

Em síntese, o argumento usado é que, se grande parte do conhecimento histórico escolar está estruturado e precisa ser conhecido, é possível acessá-lo de forma que não seja exclusivamente através da exposição do professor, mas usando alternativas de busca de informações e de uso de equipamentos para essa complementação. 
Deve-se prestar atenção nas aulas de história, as mesmas devem ser mais atrativas incorporando ou não os aparelhamentos tecnológicos, pois é notório que essa aula quando pouco atrativa perde o interesse dos alunos. Além desses desafios, soma-se a falta de planejamento pedagógico, a rigidez do currículo, a falta de recursos físicos, financeiros e a capacitação profissional.

Cabrini et al (1996, p. 19 a 23) afirma que a forma como o professor encara o processo de ensino/aprendizagem e sua concepção sobre a disciplina, definem seu método pedagógico. O professor deve ser a principal tecnologia, apesar de utilização de diversos equipamentos na criação conjunta entre os atores escolares: gestor, professor, aluno e pais, na construção do conhecimento.

Para o autor, o professor de História deve procurar atingir o máximo de alunos, apresentando meios para tornar as aulas mais atrativas. Impossível dessa forma, pensar nessa relação, sem refletir sobre qual o papel da disciplina no ensino básico, além de buscar o avanço contínuo do conhecimento.

Segundo Laville (1999, p. 19), a construção do conhecimento se faz pelos saberes espontâneos, a partir da experiência e da observação.

Portanto, se faz necessário, um professor de história que seja capaz de agregar os saberes da disciplina e as novas tecnologias para que as aulas se tornem mais atrativas para os alunos.

\section{OS RECURSOS PARA A PRÁTICA PEDAGÓGICA NA AULA DE HISTÓRIA}

Toda esta analise se fundamenta numa nova sociedade onde a informação e conhecimento são os principais instrumentos de transformação, seja no aspecto da inovação dos meios de disseminação de conteúdos e fatos, como no uso de recursos para diminuir barreiras entre o aluno e a disciplina de história. Entre alguns desses recursos para o apoio para prática pedagógica do ensino da disciplina se 
destacam o uso de projetor multimídia que pode ser utilizado para expor as aulas usando transparências ou imagens com textos, gráficos, mapas, fotografias, entre outros. Esse equipamento, é capaz de modificar a aula dando aos alunos melhores condições para o entendimento do assunto ministrado.

Essa tecnologia pode ser utilizada com exposição de textos, devendo ter clareza, de fácil leitura e sucinto, além disso, deve-se levar em consideração o nível dos alunos no sentido de proporcionar uma melhor interpretação.

Já o uso de gráficos, dão aos alunos as noções estatísticas sobre o assunto abordado. Esse uso deve priorizar a ênfase nas características especificas da pesquisa, com estimativas e referências da época em que o fato ocorreu. A ideia, é destacar fatos históricos, datas, traços e atributos sobre o assunto exposto e particularidades temporais e regionais.

Em relação ao uso de mapas, o mesmo facilita a localização de lugares, rotas, cidades, regiões, países, entre outros dados geográficos e importantes da pesquisa.

Assim, os mapas devem conter legendas visando melhor compreensão. Uma característica peculiar dos mapas é que estão em constante atualização conforme as mudanças geográficas. Os mapas também podem ser utilizados de forma comparativa, demonstrando as mudanças de relevos, políticas, organizações sociais e a evolução da sociedade.

A construção e uso de maquetes estimula a capacidade de compreensão física dos alunos. Pode ser utilizada não apenas como verificação do potencial artístico dos alunos, mas como suporte para a representação de construções históricas, buscando expor o trabalho realizado, de forma que evidencie as informações históricas importantes do contexto que está sendo abordado.

Quando o professor incorpora em suas aulas a tecnologia com o uso de fotografias, deve utilizar de forma a retratar elementos do cotidiano. Deve buscar características 
de vestimentas pessoais, arquitetura, dentre outras evidências, retratando o momento em que o fato aconteceu.

Para Le Goff (1996, p. 466), a fotografia é um novo mecanismo para reconstruir o passado e entender a evolução da humanidade, sendo assim, "uma precisão e uma verdade visual nunca antes atingida" (LE GOFF, 1996, p. 466). Essa visão do autor reflete claramente que a fotografia é um recurso capaz de apresentar de forma estática um momento histórico, essa característica torna-se um recurso importante para utilização do conhecimento.

Quanto à formação de grupo de teatro, a representação de fatos históricos na forma teatral, é um recurso capaz de provocar o senso crítico no aluno, podendo aumentar sua participação na aula. Esta ação pode movimentar vários aspectos do conhecimento como a caracterização, o figurino, o estudo do texto, a formação do cenário, entre outros. O engajamento dos alunos e a interação com o professor pode ser o ponto essencial dessa prática.

Em relação à exposição de filmes, os mesmos podem ser utilizados em situações referentes a biografias e documentários, pois servem para a abordagem de vários conteúdos da disciplina de história. Agregados aos mesmos podem ocorrer à exposição. O professor também pode solicitar ao aluno uma resenha crítica sobre o contexto histórico do filme. Essa metodologia está entre as mais utilizadas, entretanto, se o conteúdo não for bem pensado, pode desviar a atenção causando desinteresse e dispersão por parte dos alunos.

Para Pereira (2007, p. 2), o filme como recurso pedagógico precisa promover o ensino. Ver um filme é uma atividade de lazer e um prazer estético, mas, o filme selecionado para um trabalho com os alunos deve estar relacionado ao conteúdo e contribuir para o ensino da disciplina.

A questão da utilização de música nas aulas de história, apesar de parecer incomum, pode ser bastante atrativa, pois várias músicas têm letras e essas 
composições relatam temas históricos e podem ser utilizadas como apoio para a reflexão, quando se aborda assuntos e conceitos da disciplina em sala de aula.

O professor, entretanto, não precisa ser músico ou dominar nenhum instrumento musical para utilizar a música como apoio em sala de aula, mas saber relacionar a música ao assunto apresentado, elaborar questões e solicitar a resposta aos alunos, é essencial.

Em relação à charge, essas assumem a forma de representar fatos de maneira cômica e critica. Esse contexto ímpar, é capaz de trabalhar o assunto ou conceito de forma descontraída e relaxada de um tema complexo e polêmico.

Para Carvalho (2007, p. 1), em uma sala temática de história, é imprescindível a presença e a utilização didático pedagógica de imagens (fotografias, gravuras, reproduções de obras de arte, xilogravuras, charges). Segundo o autor, esses materiais possibilitam que o professor demonstre para os alunos a identificação de aspectos que caracterizam épocas, locais, povos, fatos e acontecimentos. Com esses materiais, os alunos percebem as mudanças, permanências, rupturas e semelhanças em diferentes épocas e espaços.

Em se tratando, especificamente, da disciplina de História, "o ensino atrelado a fatos históricos, datas comemorativas e heróis oficiais, torna o conteúdo algo distante do aluno" (OLIVEIRA; COSTA. 2016 pág.19). O ensino necessita ter significado para o estudante, possibilitando que o mesmo se sinta sujeito do processo histórico e, assim, poder desenvolver uma consciência histórica.

Conforme evidenciado, o uso dos recursos apresentados pode ser utilizado em qualquer disciplina, basta ter cautela e estudar o material para poder passá-lo com maior autoridade em sala de aula. Assim, alguns critérios para orientação, como recurso didático, são necessários e podem ser apresentados e utilizados pelos professores, inclusive de outras áreas. 
A quantidade e qualidade de escolha do material, o tempo de exposição, a quantidade e qualidade das informações, a quantidade e tamanho do texto, número de imagens, uso exagerado ou falta de contraste entre cores e temas devem ser verificados.

Quanto à credibilidade e confiabilidade das informações, deve-se prestar atenção a todas as fontes do material a ser apresentado. A orientação é para pesquisas serem realizadas em bases de dados cientificas, acervos de pesquisadores e documentos oficiais e os materiais áudio visuais devem ser adquiridos de fontes e produtores conhecidos.

Quanto ao controle temporal, orienta-se que a exposição de qualquer recurso complementar pelo professor não pode ultrapassar mais do que metade do tempo da aula, a outra metade deve ser reservada para as discussões e aplicação de questões referentes ao conhecimento explanado.

Dessa forma, quanto maior o tempo disponível, a utilização do método deve ser verificada. Assim, a apresentação de slides, fotos e mapas como são estáticos e objetivos podem ser utilizados quando o tempo disponível for pequeno. Se o tempo for longo, a metodologia do uso do meio teatral e filmes são mais indicados.

O domínio e segurança sobre o uso dos equipamentos utilizados e o método escolhido também é de vital importância, assim o professor deve conhecer e estar apto a manusear o material de forma plena.

Nesse sentido, o professor deve preparar sua aula e pensar em todos os detalhes tanto na escolha do método, quanto na verificação da credibilidade e confiabilidade das informações, além de verificar a eficácia através da interação com os alunos e/ou aplicação de questões.

Portanto, transformar a sala de aula em um laboratório de história é uma forma magnifica de ministrar aulas, os alunos podem se sentir parte ativa da aula, assim a sala de aula pode passar a ser um meio para o professor trabalhar melhor os 
conteúdos através de roteiros predefinidos com uso de um ou mais recursos apresentados neste estudo.

\section{CONCLUSÃO}

Ao final em relação à dúvida norteadora levantada ficou entendido que este estudo conseguiu alcançar sua pretensão de mostrar que existem práticas que se utilizam de recursos da sociedade da informação capazes de transformar a aula em um momento apropriado à motivação para a passagem do conhecimento e interação professor-aluno, apto a proporcionar melhoria na aprendizagem da disciplina de história, descartando velhos conceitos e reacendendo no aluno o desejo de estudar história.

O papel do professor é crucial para a apresentação de diferentes abordagens sobre um fato ou conceito, esta ação induz a percepção de um referencial da visão histórica apresentada sob a ótica da intenção de quem conta. Durante as aulas é impossível demonstrar todas as maneiras de ver a história, mas é fundamental demonstrar que ela não se forma através da ótica de apenas um locutor e que para todos os fatos existem também várias interpretações, esta percepção para o aluno o deixa capaz de entender as diferentes visões formadoras da cultura de uma sociedade. Para o professor, reside o principal papel de favorecer o acesso a informações, de diferentes fontes, verídicas e com credibilidade. Ter contato com estas informações amplia a visão do estudante sobre a história.

Atualmente, com a evolução nas últimas décadas, com o advento das novas tecnologias da informação e comunicação o potencial de pesquisa por parte do aluno cresceu bastante, ao passo de poder visitar museus, bibliotecas e outras fontes de informação histórica através de um computador em poucos instantes, sem limite de tempo e espaço, essa perspectiva trouxe uma abordagem mais instigadora aos alunos o que potencializa a aprendizagem. Da mesma forma, aguçam-se também numa perspectiva multidisciplinar as formas didáticas de trabalhar o ensino 
de história ao ponto de romper paradigmas e trabalhar novos conteúdos e possibilidades.

\section{REFERÊNCIAS}

ARRUDA G. Q., SILVA J. S. R., BEZERRA M. A. D. O uso da tecnologia e as dificuldades enfrentadas por educadores e educandos em meio a pandemia. VII CONEDIU Congresso Nacional de Educação. Maceió. 2020. Disponível em: https://editorarealize.com.br/editora/anais/conedu/2020/TRABALHO_EV140_MD1_S A_ID2426_04092020084651.pdf. Acesso em 22 Ago. 2021.

BRASIL. Secretaria de Educação Fundamental. Parâmetros curriculares nacionais: história, geografia. p. 29. 1997. Disponível em: http://portal.mec.gov.br/seb/arquivos/pdf/livro051.pdf. Acesso em 20 fev. 2021.

BURKE, P. Testemunha Ocular. Bauru: EDUSC, p. 13. 2004. Disponível em: < https://docero.com.br/doc/nnxessn>. Acesso em 20 fev. 2021.

CABRINI, C. (Org.). Ensino de História: revisão urgente. São Paulo: Brasiliense, 1986.

CARVALHO, L. Como compor uma sala temática de Historia? p um. 2007. Disponível em: https://educador. brasilescola.uol.com.br/estrategias-ensino/comocompor-uma-sala-tematica- historia.htm. Acesso: 13 jan. 2020.

CASSEMIRO, R. A importância das mídias no ensino de Historia. SIED Simpósio internacional de Educação à distância. ENPED. Encontro de pesquisadores em educação à distância. Belo Horizonte, p. 2. 2016. Disponível em: < http://www.siedenped2016.ead.ufscar.br/ojs/index.php/2016/article/view/1746/741> Acesso em 20 fev. 2021.

KENSKI, V. M.. Educação e tecnologias: o novo ritmo da informação. Campinas: Editora Papirus. 2012. 141p 
KOEHLER, A. L. O ensino de Historia e a fotografia como representação: uma experiência através de fontes de arquivos locais, p. 23. 2007. Disponível em: $<$ http://www.diaadiaeducacao.pr.gov.br/portals/pde/arquivos/164-4.pdf>. Acesso: 29 jan. 2020.

KNAUSS, P. O desafio de fazer História com imagens: arte e cultura visual. ArtCultura, Uberlândia, v.8, n.12, p. 109, jan/jun. 2006. Disponível em: < http://www.seer.ufu.br/index.php/artcultura/article/view/1406/1274>. Acesso em: 20 fev. 2021.

LAVILLE, C. A construção do saber: manual de metodologia da pesquisa em ciências humanas. Tradução Heloisa Monteiro e Francisco Settineri. Porto Alegre: Artmed, Belo Horizonte. Editora UFMG, p. 19. 1999. Disponível em: < https://edisciplinas.usp.br/pluginfile.php/287028/mod_resource/content/1/Laville\%2C \%20Christian\%20\%20Dionne\%2C\%20Jean_A\%20Construcao\%20do\%20Saber\%20 \%28completo\%29.pdf>. Acesso em: 20 fev. 2021.

LE GOFF, J. História e memória. Campinas, SP Editora da UNICAMP, p. 466. 1996.

OLIVEIRA, A. M.; COSTA, M. P. Utilização de histórias em quadrinhos nas aulas de história., p. 19. 2016. Cadernos PDE. Paraná. Disponível em: http://www.diaadiaeducacao.pr.gov.br/portals/cadernospde/pdebusca/producoes_pd e/2016/2016_ artigo_hist_unicentro_aliandromendesdeoliveira.pdf. Acesso em: 18 jan. 2020.

PEREIRA, W. 7 dicas de como utilizar filmes como recurso didático., p. 2. 2007. Disponível em: https://educador.brasilescola.uol.com.br/estrategias-ensino/7-dicascomo-utilizar-filmes-como- recurso-didatico.htm. Acesso: 13 fev. 2020.

TURAZZI, A.; RUFINO, E.; YUL, D.; et al. Comunicação visual do edifício e da cidade. Projetos FAU, São Paulo, v. 1, n. 1, p. 96 e 97. 2012. 
Enviado: Agosto, 2021.

Aprovado: Outubro, 2021. 